\title{
A New Theory for Ball Lightning Proposed: Aberrant Cellular Dust Discharges [Aerial Extra Corpuscular "Epilepsy"]
}

\author{
Mister Seun Ayoade* \\ College of Medicine University of Ibadan, Oyo State, Nigeria.
}

*Corresponding author: Mister Seun Ayoade, Independent Researcher. Alumnus, College of Medicine University of Ibadan, Oyo State, Nigeria. Winner, 2004 NIIT Scholarship (Grade A++).
Received Date: January 11, 2021

Published Date: February 02, 2021

\section{Opinion}

According to the Cellular Dust Hypothesis, CDH [1-2] and Seun Ayoade's Law of Living Things, S.A.L.L.T. [3] life and the universe exist due to chemical reactions carried out by ubiquitous virus sized entities variously called microzymas, cellular dust, scintillating corpuscles, molecular granulations, progenitor cryptocides, siphonospora polymorpha etc. [4] These imperishable micro entities have been hypothesized to be linked to dark matter, dark energy, phantom pain and spontaneous human combustion [5-7] but could they also be responsible for ball lightning? Theories attempting to explain ball lightning include: the Vaporized silicon hypothesis, the Electrically charged solid-core model, the Microwave cavity hypothesis, the Soliton hypothesis, Hydrodynamic vortex ring antisymmetry, the Nanobattery hypothesis, the Buoyant plasma hypothesis, Spinning plasma toroid, the Vacuum hypothesis, the Spinning electric dipole hypothesis and plasma superconductivity. However the Transcranial magnetic stimulation experiments by The Coorays [8] showed that epileptics having seizures see ball lightning during their hallucinations!

Epilepsy is caused by disordered electrical activity of the brain cells. According to the germ terrain duality theory [9-11] all cells of living things contain coordinated microzymas. In the light of this I submit that ball lightning is nothing other than irregular, bizarre electrical activity carried out by microzymas in the air i.e. public, grand outdoor "epilepsy"!

\section{Acknowledgement}

\section{Conflict of Interest}

No conflict of interest.

\section{References}

1. Seun A (2018) A New Origin of Life and the Universe ProposedMicrozymian! Peer Re J Foren \& Gen Sci 1(5).

2. Seun Ayoade (2018) Microzyman Theory of Origin (MTO)/ Cellular Dust Hypothesis (CDH)-Matters Arising. Peer Re J Foren \& Gen Sci 2(4).

3. Ayoade MS (2019) A New Natural Law Proposed - S.A.L.L.T. Anesthesiologist 1(1): 1002.

4. Ayoade S (2017) Koch's Postulates and Germ Terrain Dualism; Cellular Dust as Yet Another Term for Microzymas. J Mol Genet Med 11: 297.

5. Seun A (2018) Could Microzymas be the Elusive Dark Matter? Could Microzymas be the Force Behind Dark Energy? Peer Re J Foren \& Gen Sci 1(5).

6. Seun Ayoade (2019) Spontanous Human Combustion-Are the Microzymas The Culprit? Res \& Rev Health Care Open Acc J 3(3).

7. Seun Ayoade (2019) Another Theory for Phantom Pain. Glob J of Forensic Sci \& Med 1(5).

8. (2008) Could some ball lightning observations be optical hallucinations caused by epileptic seizures, Cooray, G. and V. Cooray, The open access atmospheric science journal: 101-105.

9. Mr. Se un Ayoade (2018) "A Few More Differences between the Theories Three" ARC Journal of Nursing and Healthcare 4(3): 1-2.

10. Mister Seun Ayoade (2017) The Differences Between the Germ Theory, the Terrain Theory and the Germ Terrrain Duality Theory; JOJ Nurse Health Care 4(2): 555631.

11. Ayoade S (2017) Germ-terrain duality of sickness, equivalent of waveparticle duality of light for the biological sciences? Bechamp revisited. Int J Anat Var 10(1): 010-11.

None. 